\title{
Recurrent primary hyperparathyroidism: a diagnostic and management dilemma
}

\section{Ben Wilkinson', Sharifah Faradila Wan Muhamad Hatta ${ }^{1,2}$, Andrew Garnham ${ }^{1}$ and Harit N Buch1}

${ }^{1}$ Royal Wolverhampton Hospital NHS Trust, Wolverhampton, UK and 2Faculty of Medicine, Universiti Teknologi MARA Sungai Buloh Campus, Sungai Buloh, Selangor, Malaysia
Correspondence should be addressed to S F Wan Muhamad Hatta Email

shfara@gmail.com

\section{Summary}

Primary hyperparathyroidism requires a surgical approach to achieve a long-term cure. However, post-surgical recurrence significantly complicates the management of this condition. A number of causes for recurrent disease are well understood and several diagnostic modalities exist to localise the culprit parathyroid adenoma although none of them is efficacious in localisation of the recurrent lesion. In this case report, we highlight a novel causative mechanism and describe a unique diagnostic sequence that enabled curative treatment to be delivered.

\section{Learning points:}

- In the case described herein, we describe a novel location for a parathyroid adenoma causing recurrent PHPT. The case elucidates well the difficulties presented by such cases in terms of surgical planning and show the utility of PVS in such cases. Based on this case, we make the following recommendations:

- Meticulous care must be taken to prevent seeding of adenomatous tissue during primary excision.

- To consider the use of PVS in patients with discordant imaging in the setting of recurrent/persistent PHPT as a method to localise the causative adenoma.

- Same day PVS and surgery is a viable option for patients who either represent an anaesthetic risk or who are extremely anxious about the prospect of two separate procedures.

- Disordered calcium homeostasis is an important but forgotten cause of dysphagia which can be extremely debilitating for affected patients.

\section{Background}

Primary hyperparathyroidism is an important cause of hypercalcaemia, most commonly caused by a parathyroid adenoma. Its clinical presentation is heterogeneous and can often be dictated by geography, as in developed healthcare systems, hypercalcaemia may be the only finding incidentally identified by multichannel analysers, while elsewhere, patients more often present with sequela of hypercalcaemia including renal calculi and osteoporotic fragility fractures. Treatment is usually surgical and now benefits from modern imaging techniques that assist the surgeons in localising the adenoma and intra-operative PTH sampling, which confirms cure during the procedure.

\section{Case presentation}

\section{Introduction}

We present the case of a 63-year-old man who required complex arrangements to complete investigations prior to surgery for recurrence of primary hyperparathyroidism (PHPT) which presented several years after the initial 
operation. The case also demonstrates an unusual cause for the recurrence and an interesting sequence of events that led to its diagnosis and successful treatment.

\section{Case description}

A 63-year-old gentleman with a known history of hypertension, managed with amlodipine $5 \mathrm{mg}$ and atenolol $25 \mathrm{mg}$ daily, presented in 2018 with recurrence of primary hyperparathyroidism. In 1996 he had presented to a neighbouring district general hospital with leftsided nephrolithiasis. He was diagnosed to have primary hyperparathyroidism with serum calcium $3.05 \mathrm{mmol} / \mathrm{L}$ (2.20-2.60 $\mathrm{mmol} / \mathrm{L})$ and parathyroid hormone (PTH) level $45 \mathrm{pmol} / \mathrm{L}$ (1.60-7.20 pmol/L). He underwent open neck exploration via transverse cervical excision in 2009 with excision of the right lower parathyroid gland. Intraoperative PTH dropped from the pre-excision level of 34.3 to $9.2 \mathrm{pmol} / \mathrm{L}$ at $15 \mathrm{~min}$ post-excision. Post-operatively his calcium normalised to $2.46 \mathrm{nmol} / \mathrm{L}$ and remained so until his last follow-up 2 years later. The histology report commented that two tan-coloured nodules were sent for histology and the second tissue, which was $7 \times 6 \times 5 \mathrm{~mm}$ in size was likely to have broken off from a larger nodule. Both confirmed the presence of a parathyroid adenoma.

He presented to us in 2018 with biochemical evidence of recurrence of PHPT (calcium $3.25 \mathrm{mmol} / \mathrm{L}$ and PTH $54.56 \mathrm{pmol} / \mathrm{L}$ ). During the preceding 2-3 years he had remained unwell with symptoms of nausea, poor appetite and gradual weight loss due to dysphagia, which was extensively investigated but no gastrointestinal pathology was identified. Clinical examination and remaining biochemical investigations were unremarkable (Table 1).

\section{Investigation}

He presented to us in 2018 with biochemical evidence of recurrence of PHPT (calcium: $3.25 \mathrm{mmol} / \mathrm{L}$ and PTH: $54.56 \mathrm{pmol} / \mathrm{L})$. During the preceding 2-3 years, he had remained unwell with symptoms of nausea, poor appetite and gradual weight loss due to dysphagia, which was extensively investigated but no gastrointestinal pathology was identified. Clinical examination and remaining biochemical investigations were unremarkable (Table 1).

In view of increasing symptoms and rising calcium level, he was prescribed Cinacalcet. Unfortunately, in view of the dysphagia, he was unable to swallow tablets regularly and required in-hospital management with intravenous $0.9 \%$ saline and Pamidronate. Over the next
Table 1 Biochemical parameters at presentation with recurrent PHPT.

\begin{tabular}{|c|c|c|}
\hline Parameters & Results & Normal values \\
\hline Corrected calcium, mmol/L & 3.25 & $2.20-2.60$ \\
\hline Phosphate, nmol/L & 0.60 & $0.80-1.50$ \\
\hline PTH, pmol/L & 54.56 & $1.60-7.20$ \\
\hline Sodium, mmol/L & 144 & $133-146$ \\
\hline Potassium, $\mathrm{mmol} / \mathrm{L}$ & 4.8 & $3.5-5.3$ \\
\hline Urea, mmol/L & 4.0 & $2.5-7.8$ \\
\hline Creatinine, $\mu \mathrm{mol} / \mathrm{L}$ & 102 & $64-111$ \\
\hline Prostate-specific antigen, $\mu \mathrm{g} / \mathrm{L}$ & 1.41 & $0-4.10$ \\
\hline Haemoglobin, g/L & 145 & $130-180$ \\
\hline White cell count, $\times 109 / \mathrm{L}$ & 7.8 & $4.0-11.0$ \\
\hline Platelet count, × 109/L & 216 & $150-450$ \\
\hline Serum electrophoresis & $\begin{array}{c}\text { No paraprotein } \\
\text { detected }\end{array}$ & \\
\hline Vitamin D3, nmol/L & 46.9 & $>50$ \\
\hline
\end{tabular}

few months, he required further hospital admissions for intravenous therapy at increasing frequency.

Ultrasound scan (US) revealed a possible $5 \mathrm{~mm}$ adenoma at the right inferior thyroid pole (Fig. 1). Parathyroid scintigraphy failed to demonstrate any focal persistent uptake in the region of the parathyroid glands, or elsewhere, to suggest an adenoma (Fig. 2). This

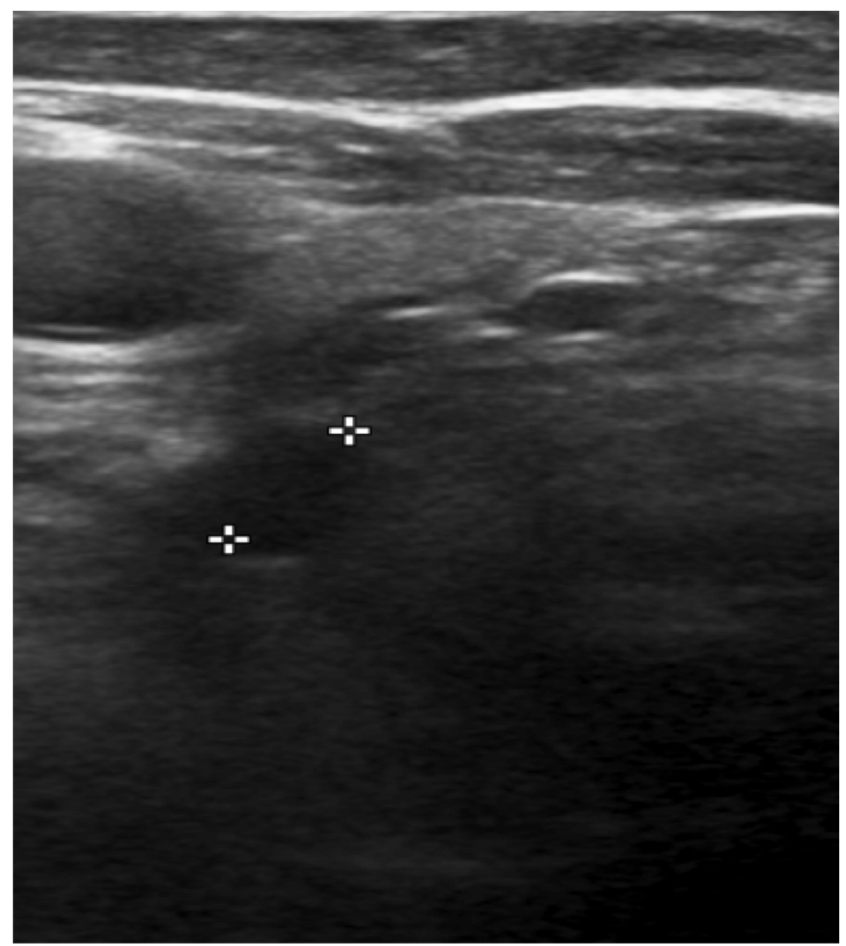

Figure 1

Image captured from US neck showing possible $5 \mathrm{~mm}$ adenoma at the right inferior thyroid pole but this was equivocal. 


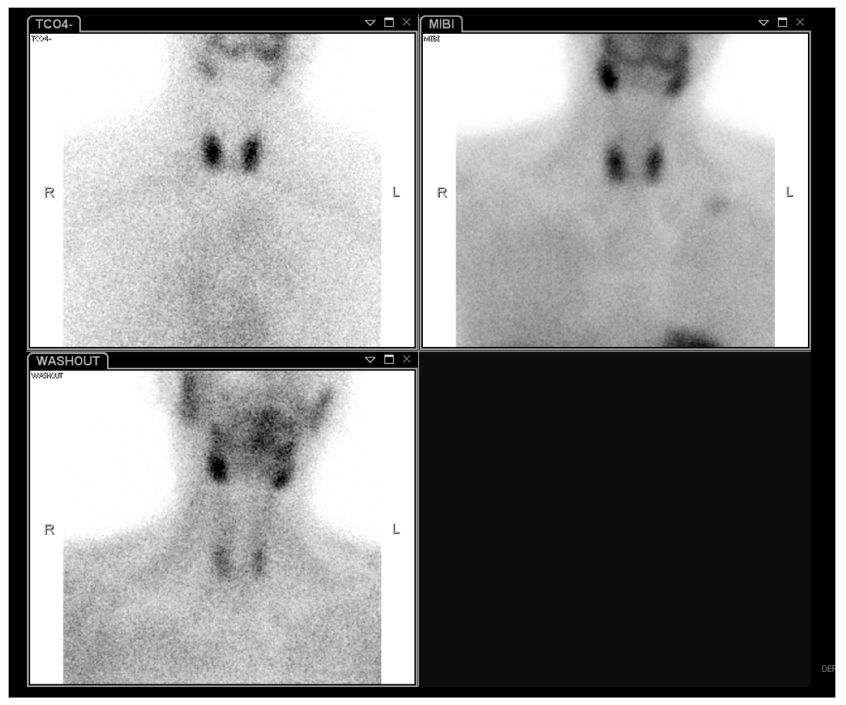

Figure 2

Image captured from parathyroid scintigraphy which failed to demonstrate any focal persistent uptake in the region of the parathyroid glands, or elsewhere, to suggest an adenoma.

presented a clinical quandary for the surgeons, as in the absence of definite localisation, neck exploration was deemed to carry a higher local risk in view of previous open neck exploration with subsequent local fibrosis.

In order to localise the region of the pathology, parathyroid venous sampling (PVS) was planned. However, the patient was unwilling to have this procedure without the use of general anaesthesia (GA). In addition to being a clinical risk, the use of GA for PVS in the interventional suite was a logistic and resource challenge. Finally, after much debate, it was organised as a combined procedure along with focused neck exploration obviating the need to have two separate spells under GA. The results of PTH values were made available within the next few minutes so as to facilitate the surgical procedure, scheduled to immediately follow PVS.

The US scan had already identified a lesion and parathyroid venous sampling (PVS) was deemed necessary in view of significant local scarring related to the previous surgery. In view of this, we did not undertake another form of imaging. The patient was also quite anxious about investigations, which led to the PVS being performed under GA administered for surgery.

No complications occurred during PVS, which showed a gradient at the Left Innominate (Fig. 3).

\section{Treatment}

During the surgical procedure, the left lower parathyroid gland appeared normal. However,

\begin{tabular}{|c|c|c|c|}
\hline $\begin{array}{l}\text { PTH } \\
\text { pmol/L }\end{array}$ & Site & $\begin{array}{l}\text { PTH } \\
\text { pmol/L }\end{array}$ & Site \\
\hline 1. 38.40 & R high intemal jugular & II. 3339 & L mid intemal jugular \\
\hline 2. 37.52 & $R$ mid intemal jugulat & I2. 31.41 & L lower intemal jugular \\
\hline 3.36 .43 & R low intemal jugular & 13.32 .17 & L proximal innominate \\
\hline 4. & & 14.45 .41 & L mid-proximal innominate \\
\hline 5. 34.66 & $R$ very low intemal jugular & 15.3230 & L distal innominate \\
\hline 6. 4292 & R innominate & 16.52 .21 & Confluence of $L$ innominate \\
\hline 7.33 .35 & L low intemal jurular & 17.4893 & Mad SVC \\
\hline 8.32 .34 & I lower collateral & 18.47 .60 & Junction of SVC and R atrium \\
\hline 9.3394 & I lowet neck venous network & 19.34 .06 & Level of $\mathrm{R}$ atrium \\
\hline 10.32 .29 & I high intemal jugular & 20.28 .32 & High IVC \\
\hline
\end{tabular}

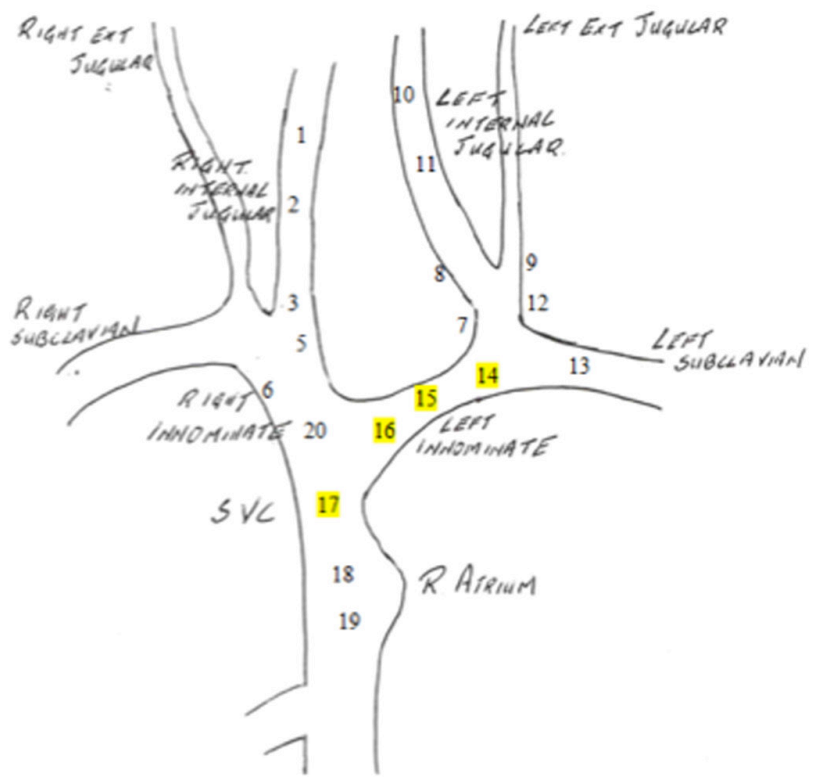

Figure 3

PVS template showing PTH gradient at the Left Innominate (highlighted in yellow).

an abnormal lesion was identified, on the left subplastysmal flap when it was elevated. Frozen section of the lesion confirmed it to be parathyroid tissue. The size of the lesion was $15 \mathrm{~mm} \times 10 \mathrm{~mm} \times 4 \mathrm{~mm}$ and weighing $0.2 \mathrm{~g}$.

Following the excision of this nodule, PTH level dropped from $52.21 \mathrm{pmol} / \mathrm{L}$ at baseline to $8.04 \mathrm{pmol} / \mathrm{L}$ at $20 \mathrm{~min}$ post-removal ( $>50 \%$ reduction) suggestive of a successful surgery. Histology confirmed the presence of a parathyroid adenoma.

\section{Outcome and follow-up}

Post-surgery, calcium level normalised and it has remained between 2.20 and $2.40 \mathrm{pmol} / \mathrm{L}$. The patient is now well with good appetite, normal swallowing associated with healthy weight gain. He remains under 6 monthly follow-ups from the endocrinology team. Follow-up duration at the time of writing of this case report was 6 months. 


\section{Discussion}

PHPT is a common endocrine condition with a prevalence of $0.1-1 \%$, with female to male ratio of $4: 1$ (1). It is frequently detected in asymptomatic patients during routine biochemical tests. Early detection and wellestablished guidelines for management have resulted in a reduction in cases of late and severe presentations with crippling osteoporosis, fragility fractures, renal calculi and neuropsychiatric symptoms (2). It usually results from a solitary parathyroid adenoma in $85 \%$ of cases, with multigland disease seen in approximately $10-15 \%$ of patients (3). In patients who are symptomatic as well in those asymptomatic patients who meet the widely accepted international criteria based on patient's age, skeletal, renal and biochemical features, parathyroidectomy following preoperative localisation of the adenoma is the only definitive treatment (2).

Preoperative localisation is routinely undertaken to facilitate localised surgery and thereby increase the cure rate, decrease perioperative complications and operating time (4). Wider cervical dissection is associated with a higher risk of recurrent laryngeal nerve injury (OR 0.33 ) and post-operative hypocalcaemia (OR 0.36) (5). Non-invasive imaging modalities include ultrasound (US), parathyroid scintigraphy using 99m-technetium sestamibi (RN), 4-dimensional CT (4D-CT), and rarely MRI. The concordance rate between US and RN imaging is reported to be $>70 \%$ (6) although in patients who are being assessed prior to a reoperation, concordance rates as low as 30\% have been reported (7). In view of this, in such clinical settings, invasive investigations are often needed to localise the lesion.

The commonest invasive investigation undertaken is parathyroid venous sampling (PVS) which is an angiographic procedure usually undertaken in patients who have previously had neck surgery resulting in scarring and obliteration of tissue planes. These changes lead to an increase in the risk of injury to the recurrent laryngeal nerve and a higher rate of operative failure. PVS detects a unilateral PTH gradient by sampling multiple sites within the veins that drain the parathyroid glands (Fig. 3). It can be performed by one of three methods: (i) Selective venous sampling with samples obtained only from large central neck veins (jugular, subclavian and innominate veins) as conducted in our patient, (ii) super-selective venous sampling with sampling of smaller neck veins (superior, middle and inferior thyroid veins) and (iii) direct percutaneous bilateral internal jugular venous sampling. Lateralisation and regionalisation of the culprit lesion are indicated by a 1.5 - to 2 -fold increase in PTH level obtained from a known vascular territory as compared to a peripheral location (8). It has the greatest sensitivity as compared to other localisation techniques in patients undergoing revision surgery with reported sensitivity as high as 95\% (9). This is supported in a recent meta-analysis which reported that sensitivity, positive likelihood ratio (PLR) and positive post-test probability of PVS were between 75 and 95\% which are significantly higher compared to non-invasive imaging modalities (10). These figures rise further to $>90 \%$ when PVS is combined with 4D-CT (11). However, despite its success, concerns about its invasiveness have prevented PVS to be recommended or used routinely.

A decision was made in our patient to undertake PVS in view of the history of previous neck surgery, equivocal US findings and negative RN scan. This procedure is usually conducted under local anaesthesia. However in our patient, in view of his reluctance to have the procedure done without GA, we arranged for it to be done immediately prior to surgery. Both procedures, that is, PVS and neck exploration were completed during a single period of GA administration. It proved to be logistically challenging to coordinate input from multiple specialists including the interventional radiologist, clinical biochemist, anaesthetist, endocrine surgeon and endocrinologist and ensure timely availability of results for the test to have an impact on the surgical approach. It proved to be an important investigation as the abnormal gradient in the left innominate area allowed the surgeon to avoid the previously explored right side of the neck and aim for a targetted dissection. Upon raising the subplatysmal flaps, an abnormal nodule was found in the scar tissue of the lower flap. This was resected and the frozen section confirmed parathyroid tissue. The neck was further explored on the left side revealing normal glands and in view of a drop in intra-operative PTH of $>50 \%$ upon removal of the abnormal nodule on the left subplatysmal flap, the neck was closed.

The location of the gland in our patient was not along these tracts or at one of the other usual sites. In view of this, we believe that the parathyroid adenoma located on the left subplastysmal flap was not an ectopic gland but was the result of seeding that occurred during the initial surgery resulting in a parathyromatosis-like picture. In addition to the highly unusual location, there was another clue to support this possibility. The histology report from the first parathyroidectomy had commented that two tancoloured nodules were sent for histology and the second tissue, which was $7 \times 6 \times 5 \mathrm{~mm}$ in size was likely to have 
broken off from the larger tissue/nodule. The only feature that was unusual for seeding was the presence of a single isolated area of adenomatous tissue rather than a diffuse disease as is more often encountered.

This is the first case report to describe this sequence necessitated by patient's choice and clinical complexity. The patient we have described highlights the following interesting features about the presentation, investigation and management of patients with recurrent hyperparathyroidism.

\section{Conclusion}

We present an interesting case of recurrent PHPT due to a parathyroid adenoma identified at a previously undescribed location. We strongly believe that the finding at this location was the result of seeding at the initial procedure as its location fell outside of the anatomical regions where surgeons can expect to find a typical or an ectopic adenoma. Our case also highlights the benefits of PVS in achieving a successful outcome especially in a selected complex case like ours.

\section{Declaration of interest}

The authors declare that there is no conflict of interest that could be perceived as prejudicing the impartiality of the research reported.

\section{Funding}

This research did not receive any specific grant from any funding agency in the public, commercial or not-for-profit sector.

\section{Patient consent}

Written informed consent for publication of the patient's clinical details was obtained from the patient.

\section{Author contribution statement}

Ben wilkinson - writing; Sharifah Faradila Wan Muhamad Hatta - case detection, medical management of the case, writing and editing of manuscript; Andrew Garnham - surgical management of the case; Harit N Buch - medical management of the case, writing and editing of the manuscript.

\section{References}

1 Bilezikian JP, Bandeira L, Khan A \& Cusano NE. Hyperparathyroidism. Lancet 2018391 168-178. (https://doi. org/10.1016/S0140-6736(17)31430-7)

2 Bilezikian JP, Brandi ML, Eastell R, Silverberg SJ, Udelsman R, Marcocci C \& Potts JT. Guidelines for the management of asymptomatic primary hyperparathyroidism: summary statement from the fourth international workshop. Journal of Clinical Endocrinology and Metabolism 201499 3561-3569. (https://doi. org/10.1210/jc.2014-1413)

3 Bilezikian J, Marcus R, Levine M, Marococci C, Silverberg S \& Potts J. The Parathyroids. Amsterdam: Elsevier/AP, Academic Press is an imprint of Elsevier 2015.

4 Reid L, Muthukrishnan B, Patel D, Crane M, Akyol M, Thomson A, Seckl JR \& Gibb FW. Presentation, diagnostic assessment and surgical outcomes in primary hyperparathyroidism: a single centre's experience. Endocrine Connections 20187 1105-1115. (https://doi. org/10.1530/EC-18-0195)

5 Norman J \& Denham D. Minimally invasive radioguided parathyroidectomy in the reoperative neck. Surgery $1998 \mathbf{1 2 4}$ 1088-1093. (https://doi.org/10.1067/msy.1998.92007)

6 Sukan A, Reyhan M, Aydin M, Yapar AF, Sert Y, Canpolat T \& Aktas A. Preoperative evaluation of hyperparathyroidism: the role of dualphase parathyroid scintigraphy and ultrasound imaging. Annals of Nuclear Medicine 200822 123-131. (https://doi.org/10.1007/s12149007-0086-z)

7 Yen TW, Wang TS, Doffek KM, Krzywda EA \& Wilson SD. Reoperative parathyroidectomy: an algorithm for imaging and monitoring of intraoperative parathyroid hormone levels that results in a successful focused approach. Surgery 2008144 611-621. (https://doi. org/10.1016/j.surg.2008.06.017)

8 Lebastchi AH, Aruny JE, Donovan PI, Quinn CE, Callender GG, Carling T \& Udelsman R. Real-time super selective venous sampling in remedial parathyroid surgery. Journal of the American College of Surgeons 2015220 994-1000. (https://doi.org/10.1016/j. jamcollsurg.2015.01.004)

9 Taslakian B, Trerotola SO, Sacks B, Oklu R \& Deipolyi A. The essentials of parathyroid hormone venous sampling. Cardiovascular and Interventional Radiology 201740 9-21. (https://doi.org/10.1007/ s00270-016-1481-4)

10 Ibraheem K, Toraih EA, Haddad AB, Farag M, Randolph GW $\&$ Kandil E. Selective parathyroid venous sampling in primary hyperparathyroidism: a systematic review and meta-analysis. Laryngoscope 2018128 2662-2667. (https://doi.org/10.1002/ lary.27213)

11 Sun PY, Thompson SM, Andrews JC, Wermers RA, McKenzie TJ, Richards ML, Farley DR \& Thompson GB. Selective parathyroid hormone venous sampling in patients with persistent or recurrent primary hyperparathyroidism and negative, equivocal or discordant noninvasive imaging. World Journal of Surgery 201640 2956-2963. (https://doi.org/10.1007/s00268-016-3621-z)

Received in final form 1 March 2021 Accepted 2 April 2021 